\title{
Estrogen Receptor Status
}

National Cancer Institute

\section{Source}

National Cancer Institute. Estrogen Receptor Status. NCI Thesaurus. Code C16150.

The estrogen receptor level measured in a primary tumor or in metastases. There are essentially two distinct forms of breast cancer, one that tends to have an early onset and is characterized by an ER- status, and one that tends to have a late onset and is characterized by an ER+ status. However, these two variants tend to overlap with respect to age, so it is possible for a young woman to have a "late-onset" form of breast cancer and for an older woman to have an "early-onset" variant of the disease. 